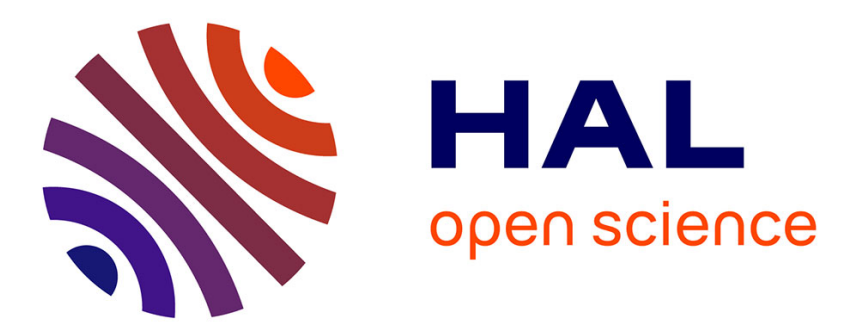

\title{
Statistical analyses of repolarisation current of a PZT film deposited on ITO electrode with different thermal treatments
}

Salvatore Marino, Andrei Th Ionescu, Anca-Luiza Alexe-Ionescu, Gaetano Nicastro, Giuseppe Strangi, Nicola Scaramuzza

\section{To cite this version:}

Salvatore Marino, Andrei Th Ionescu, Anca-Luiza Alexe-Ionescu, Gaetano Nicastro, Giuseppe Strangi, et al.. Statistical analyses of repolarisation current of a PZT film deposited on ITO electrode with different thermal treatments. Philosophical Magazine, 2010, 90 (12), pp.1575-1584. 10.1080/14786430903419091. hal-00587608

\section{HAL Id: hal-00587608 https://hal.science/hal-00587608}

Submitted on 21 Apr 2011

HAL is a multi-disciplinary open access archive for the deposit and dissemination of scientific research documents, whether they are published or not. The documents may come from teaching and research institutions in France or abroad, or from public or private research centers.
L'archive ouverte pluridisciplinaire HAL, est destinée au dépôt et à la diffusion de documents scientifiques de niveau recherche, publiés ou non, émanant des établissements d'enseignement et de recherche français ou étrangers, des laboratoires publics ou privés. 


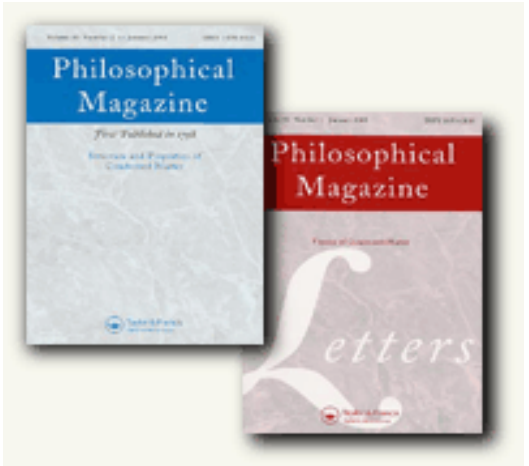

\section{Statistical analyses of repolarisation current of a PZT film deposited on ITO electrode with different thermal treatments}

\begin{tabular}{|c|c|}
\hline Journal: & Philosophical Magazine \& Philosophical Magazine Letters \\
\hline Manuscript ID: & TPHM-09-Jun-0256.R1 \\
\hline Journal Selection: & Philosophical Magazine \\
\hline $\begin{array}{r}\text { Date Submitted by the } \\
\text { Author: }\end{array}$ & 01-Sep-2009 \\
\hline Complete List of Authors: & $\begin{array}{l}\text { marino, salvatore; University of Calabria, department of physics } \\
\text { Ionescu, Andrei; Universitatea din Bucuresti, Facultatea de Fizica } \\
\text { Alexe-Ionescu, Anca-Luiza; Universitatea "Politehnica" din } \\
\text { Bucuresti, Faculatea de Stiinte Aplicate } \\
\text { nicastro, gaetano; University of Calabria, department of physics } \\
\text { strangi, giuseppe; University of Calabria, department of physics } \\
\text { Scaramuzza, Nicola; University of Calabria, department of physics }\end{array}$ \\
\hline Keywords: & ferroelectrics, PZT, statistical physics \\
\hline Keywords (user supplied): & \\
\hline
\end{tabular}

\section{ScholaroNE}




\section{Statistical analyses of repolarisation current of a PZT film deposited on ITO electrode with different thermal treatments.}

Salvatore Marino ${ }^{1}$, Andrei Th. Ionescu ${ }^{2}$, Anca-Luiza Alexe-Ionescu ${ }^{3}$, Gaetano Nicastro ${ }^{1}$, Giuseppe Strangi ${ }^{1}$ and Nicola Scaramuzza ${ }^{1, *}$

1) INFM-CNR-LICRYL Laboratory-CEMIF.CAL, Department of Physics University of Calabria, Via P. Bucci, Cubo 33B, 87036 Rende (CS) Italy

2) Facultatea de Fizica, Universitatea din Bucuresti, P.O.B MG-11, Ro-077125 Bucharest, Romania

3) Faculatea de Stiinte Aplicate, Universitatea "Politehnica" din Bucuresti, Splaiul Independentei 313, Ro-060042 Bucharest, Romania

*) Corresponding author. Tel.: (+39) 0984-496113 Fax. (+39) 0984-494401 E-mail: scaramuzza@fis.unical.it 


\begin{abstract}
In the vast application fields of PZT (lead zirconium titanate) thin films, of particular interest are the interaction effects occurring at the ferroelectric - substrate interface $[1,2]$. Relevant for this purpose are polarity sensitive liquid crystals (LC) cells, micro and nano-electronic applications [3]. In the present work the polarization current of a PZT film $\left(\mathrm{PbZ}_{\mathrm{r} 0,47} \mathrm{~T}_{\mathrm{i} 0,53} \mathrm{O}_{3}\right)$, obtained by sol-gel synthesis and deposited by spin coating on ITO (indium tin oxide) electrode, has been studied. The different behaviour showed by such a system when the support electrode is previously submitted to a thermal treatment could be attributed to the change of the electrical properties of the ITO layer. In particular, a higher negative charge in the conductive band of the ITO electrode seems to be responsible of a higher order in the ferroelectric film.
\end{abstract}

Keywords: PZT film, repolarisation current, thermal treatments, Ferroelectric properties

PACS: 77.00.00, 42.70.Mp, 77.90.+k, 03.75.Hh, 81.20.Fw 


\section{Introduction}

PZT is a well known material for its ferroelectric properties that are suitable for a large number of applications as non-volatile ferroelectric memories, sensors [4,5] and so on [6-11]. Recently, thin films of PZT have been used to create asymmetric nematic liquid crystal cells (ANLC) in order to obtain a polarity sensitive electrooptical response. The advantage of such cells consists in controlling both ON and OFF states by an external field, consequently reducing the switching time [1]. The electro-optical response obtained with ANLCs containing PZT thin films was very interesting in terms of response time, contrast and rectifying effect. Such behaviour had been ascribed to the ferroelectric nature of the PZT film and to the interlayer phenomena occurring at the PZT-ITO interface that are responsible for a favoured orientation of the PZT nanodomains and, consequently, for the polar sensitive response of the liquid crystal layer. In this work the repolarisation current of PZT thin film obtained by sol-gel synthesis has been studied in two different cases. In the first case the PZT film has been deposited on an ITO electrode deprived of whatever thermal treatment and subsequently submitted to a heating of $600^{\circ} \mathrm{C}$ for $1 \mathrm{~h}$ in order to ensure the transition to the ferroelectric perovskite phase. In the second case the ITO electrode has been previously submitted to a thermal treatment of $700^{\circ} \mathrm{C}$ in order to induce a change of its electric properties, then covered by the sol-gel process and eventually heated at $600^{\circ} \mathrm{C}$ for $1 \mathrm{~h}$. Interesting conclusions have been drawn from the 
comparison between the behaviours of the repolarisation current showed by these samples.

\section{Experimental setup}

The repolarisation currents of PZT film were investigated using the setup described in Fig.1. The ITO substrate is connected to the output of a voltage source (Wavetek Universal Waveform Generator model 195). The signal applied to the electrode was a triangular wave with a $1 \mathrm{~s}$ period. The upper electrode of cylindrical shape and $1 \mathrm{~cm}$ in diameter was placed with one of its optically polished bases directly in contact to the PZT film (the contact pressure was provided by the very weight of the copper cube). This electrode is connected to the ground by a rather small and well known resistor $(100 \Omega)$. The voltages drop on this resistor, measured and recorded by a high input impedance oscilloscope (Agilent Infiniium 54832D MSO), is directly proportional to the electric current through the PZT film. To minimize the noise, the measuring setup (substrate, PZT film, upper electrode, and the measuring resistor) was surrounded by a grounded Faraday cage (not shown in the figure). Another channel of the oscilloscope was used to visualize and record the applied triangular wave, this last one also serving to trigger the oscilloscope. For each frequency two sets of data have been recorded, allowing representing currents and voltages versus time. The digitized sets of data are amenable to several kind of mathematical processing (for instance: peak area integration, smoothing, curve fitting, etc.). All the measurements have been performed at room temperature. 
We have used a rather large upper electrode because we are concerned of repolarization measurements. The repolarization is controlled by the electric field in the PZT and, therefore, we tried to create a thin planar condenser between the ITO substrate and the polished copper surface. We are not interested in having good ohmic contacts on totp of PZT free surface, on the contrary. Actually, the ohmic current is very small as one can easily see from Fig.2, analyzing the slopes of the currents for the two regimes of the triangular signal (increasing and decreasing). On the other hand, the dielectric displacement current change is quite evident at the time instants where the two regimes of the triangular signal change the slopes. On top of this two currents there appear the ferroelectric repolarization currents manifested as two narrow peaks.

. In Fig.2 is reported the voltage-current vs time plot. The two peaks of the current flowing trough the PZT (open circle) that appear in correspondence of around $+40 \mathrm{~V}$ and $-29 \mathrm{~V}$ of the applied voltage (black line) are due to the switch of the ferroelectric dipole. Since the applied signal includes 200 cycles we have 400 repolarisation switches (200 for positive polarity and 200 for negative one) that are enough to do statistical analyses. From such measurement has been possible to carry out information about the intensity of the repolarisation current (peak height), the voltage value at which the repolarisation switches happens and the repolarisation switching time (peak width measured at the base).

\section{Results and discussion}


The peak height variation as function of the time, measured for both polarities of the applied voltage, is shown in Fig.3, while in Fig.4 are shown the same measurements for the ITO electrode submitted to a previous thermal treatment at $700^{\circ} \mathrm{C}$. Comparing these results it is evident that in the first case a higher correlation between the experimental data is present, in particular the peak height occurring during the negative polarity of the applied voltage. Such difference could be attributed to a higher order of the ferroelectric nanodomain orientation in the first case with respect to the second case.

In Fig.5 are showed the histograms related to the value of the applied voltage at which the repolarisation switches appear both for positive and negative polarity when the ITO electrode has not been thermally treated. It is possible to notice that for negative polarity (ITO negatively charged) the distribution of voltage values at which the polar switch happens, within a quite narrow range, centres around $33 \mathrm{~V}$. On the contrary, for positive polarity the distribution is rather wide and centres on $18 \mathrm{~V}$.

In Fig. 6 the switching time histograms of the ferroelectric repolarisation are reported both for positive and negative polarization of the ITO not thermally treated. In this case also it is possible to notice a remarkable difference between the opposite polarities. In fact, for negative polarity the switching time distribution has a narrow range cantered around $0.02 \mathrm{~s}$, while for positive polarity the switching time distribution is wider and cantered on $0.04 \mathrm{~s}$. What can be deduced by these data is that when the ITO electrode is negatively charged the ferroelectric repolarisation appears in a faster and cooperative way that when the ITO electrode is positively charged. 
The same histograms have been drawn for the sample in which the ITO electrode has been previously annealed at $700^{\circ} \mathrm{C}$. The histograms related to the value of the applied voltage at which the repolarisation switch happens for both positive and negative polarity are reported in Fig.7. A remarkable difference from the precedent case is that now the required voltage to command the polar switch is higher. In fact, for positive polarity, the distribution is cantered on $60 \mathrm{~V}$ while, for the negative one, around $43 \mathrm{~V}$, moreover, the two distributions are not so different in width as the preceding ones. As the ferroelectric switching time is concerned (see fig.8), in the last case we still observe narrowed distribution for negative polarity respect to the positive one, but the average switching time is similar, in fact both positive and negative polarity distributions are cantered around $0.01 \mathrm{~s}$.

\section{Conclusions}

In this work the switching properties of $\mathrm{PbZr}_{0.47} \mathrm{Ti}_{0.53} \mathrm{O}_{3}$ (PZT) ferroelectric films were studied. Such films was obtained by sol-gel synthesis and deposited on ITO covered glass substrates by spin coating deposition and submitted to a thermal treatment at $600^{\circ} \mathrm{C}$ for one hour to ensure the transition to the perovskite phase. The analysis of the repolarisation current was effectuate on two different kinds of samples: in one of them the bottom electrode was previously submitted to a thermal treatment at $700^{\circ} \mathrm{C}$ in order to induce a structural modification of the ITO layer, while in the other one the substrate was thermally untreated. From the statistical analysis can be deduced that, in the case of the sample having the ITO electrode untreated, the 
polar switch occurring when the ITO electrode is negatively charged appears in a faster and cooperative way than the ITO electrode is positively charged. This difference was less evident for the other sample, moreover, even in this last case, an increased value of the voltage at which the ferroelectric switch happen was observed for both polarities. Such information, together with the distribution shapes, suggests that the structure modification induced on the ITO film by the thermal treatment is responsible of a higher disorder of the nanodomain polarization. A possible explanation of this behaviour should take into account the influence of the annealing on the ITO charge carriers. In particular, we can imagine the fact that ITO/PZT interface is not just a geometric dividing plane but it allows injection of electrons into the PZT film. For instance, with negative polarity applied to ITO side of the sample not only the ITO film has got an influx of electrons but also the PZT. As both zirconium and titanium are transition metals there are d-type orbitals that can accept extra electrons. The twin potential walls, typical for ferroelectric materials, go deeper and the potential barrier increase (see fig.9). On the contrary, the positive potential extracts electrons also from PZT and the barrier lowers permitting the electric dipoles to flip over at a smaller voltage. This synergic bond mechanism [12] is consistent to the nefelauxetic effect seen in transition metal complexes as an auxiliary contribution to the usual ionic ligand field.

When the ITO substrate was previously treated up, its electrical properties worsen, the permeability of electrons to PZT diminishes and the histograms cannot show clearly the effect. 


\section{Acknowledgements}

The authors are greatly indebted to Professor R. Bartolino for his helpful discussions. 


\section{References}

[1] E. Bruno, M.P. De Santo, M. Castriota, S. Marino, G. Strangi, E. Cazzanelli, and

N. Scaramuzza: "Morphological and electrical investigations of lead zirconium titanate thin films obtained by sol-gel synthesis on indium tin oxide electrodes". Journal of Applied Physics. 103, (2008) p. 064103

[2] Dunn S., Whatmore R.W: "Substrate effects on domain structures of PZT 30/70 sol-gel films via PiezoAFM". Journal of the European Ceramic Society 22 (6), (2002) p. 825

[3] S Marino, M. Castriota, G. Strangi, E. Cazzanelli, N. Scaramuzza: “Asymmetric nematic liquid crystal cells containing lead zirconium titanate (PZT) films". Journal of Applied Physics. 102 (2007) p. 013112. Selected for Virtual Journal of Nanoscale Science \& Technology July 30, 2007.

[4] Takasu, Hidemi "The Ferroelectric Memory and its Applications". Journal of Electroceramics 4(2), (2000) p. 327

[5] Cima Lionel, Remiens Denis: "Ferroelectric active sensors". Sensors and Actuators A: Physical 119 (1), (2005) p. 120 
[6] D. A. Van den Ende, P. De Almeida, Sybrand Van der Zwaag: "Piezoelectric and mechanical properties of novel composites of PZT and a liquid crystalline thermosetting resin”. Journal of materials science 42(15), (2007) p. 6417

[7] Wei Zhang, Di Lou, Jian Bai, Hui Ye and Guoguang Yang : "Study of a deformable micro-mirror based on PZT films". J. Opt. A: Pure Appl. Opt. , 9, (2007) p. 1014

[8] V.V. Shvartsman, N. A. Pertsev, J. M. Herrero, C. Zaldo, A.L. Kholkin: “ Nonlinear local piezoelectric deformation in ferroelectric thin films studied by scanning force microscopy". Journal of Applied Physics 97, (2005) p. 104105

[9] M. Dawbwr, K. M. Rabe, J. F. Scott: "Physics of thin-film ferroelectric oxides". Reviews of Modern Physics 77, (2005) p. 1083

[10] Chen Zhu, Zeng Yong, Yang Chentao, Yang Bangchao: "Investigation the effects of the excess Pb content and annealing conditions on the microstructure and ferroelectric properties of PZT (52-48) films prepared by sol-gel method". Applied Surface Science 253(3), (2006) p. 1500 
[11] Dage liu, Chen Wang, Hongxi Zhang, Junwei Li, Liancheng Zhao, Chunli Bai.” Domain configuration and interface structure analysis of sol-gel-derived PZT ferroelectric thin films". Surface and Interface Analysis 32, (2001) p. 27

[12] J. E. Huheey, E. A. Keiter, R. L. Keiter : "INORGANIC CHEMISTRY: PRINCIPLES OF STRUCTURE AND REACTIVITY”. $4^{\text {th }}$ edition Prentice Hall, 1997 New Jersey. 


\title{
Figure captions
}

Fig.1 Repolarization current setup . $\mathrm{r}$ is the measuring resistor.

Fig.2 $1 \mathrm{~s}$ part out of the $200 \mathrm{~s}$ plot. The black line is the applied voltage, the open circles are the current flowing through the PZT film.

\begin{abstract}
Fig.3 Peaks height as function of time (sample with the substrate previously untreated). The black squares are referred to the positive polarity, while the open circles to the negative one.
\end{abstract}

Fig.4 Peaks height as function of time (sample with the substrate previously treated). The black squares are referred to the positive polarity, while the open circles to the negative one.

Fig.5 Voltage value histograms at which the repolarization happens. Positive polarity (a), negative polarity (b). (Sample with the substrate previously untreated).

Fig.6 Switching time histograms. Positive polarity (a), negative polarity (b). (Sample with the substrate previously untreated). 
Fig.7 Voltage value histograms at which the repolarization happen. Positive polarity (a), negative polarity (b). (Sample with the substrate previously treated).

Fig.8 Switching time histograms. Positive polarity (a), negative polarity (b). (Sample with the substrate previously treated).

Fig.9 Twin potential walls for a ferroelectric material in an ideal symmetric condition (a) and with the electrons contribution (b). 


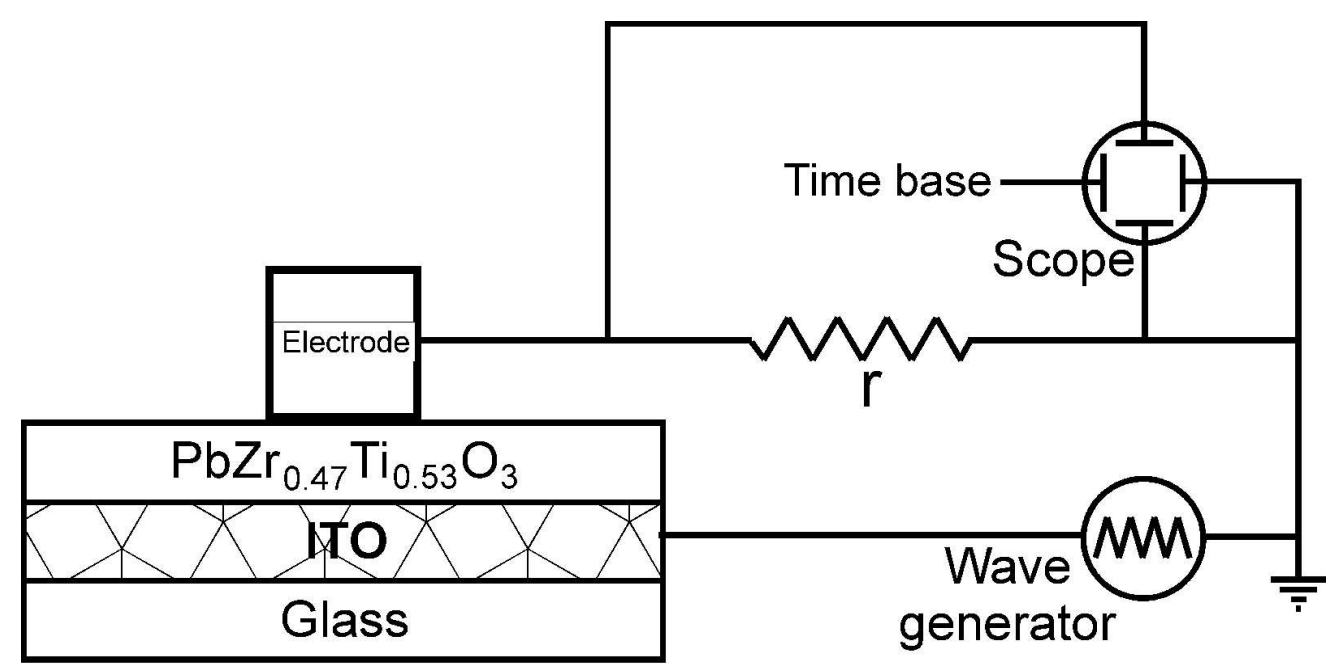

Figure 1

fig. 1

$163 \times 110 \mathrm{~mm}(500 \times 500$ DPI $)$ 


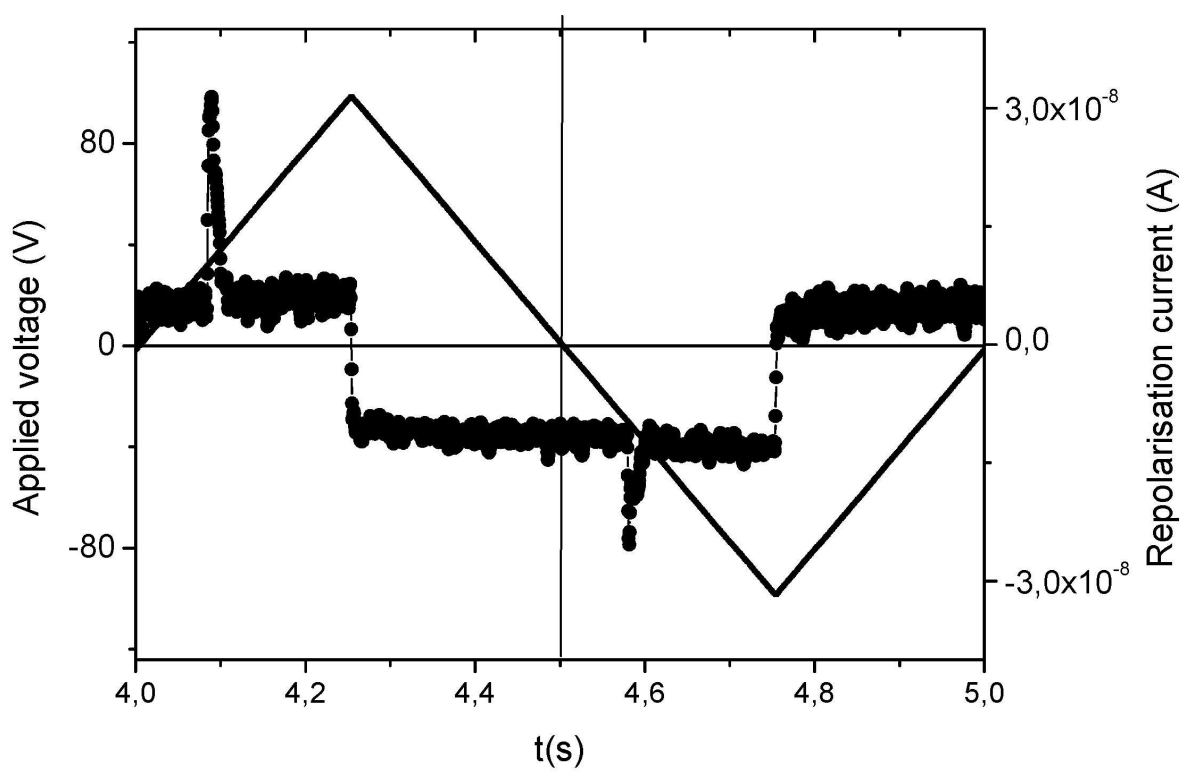

\section{FIGURE 2}

fig 2

$124 \times 93 \mathrm{~mm}(500 \times 500 \mathrm{DPI})$

34

35

36

37

38

39

40

41

42

43

44

45

46

47

48

49

50

51

52

53

54

55

56

57

58

59

60 


\section{FIGURE 3}

fig 3

$112 \times 96 \mathrm{~mm}(500 \times 500$ DPI $)$ 


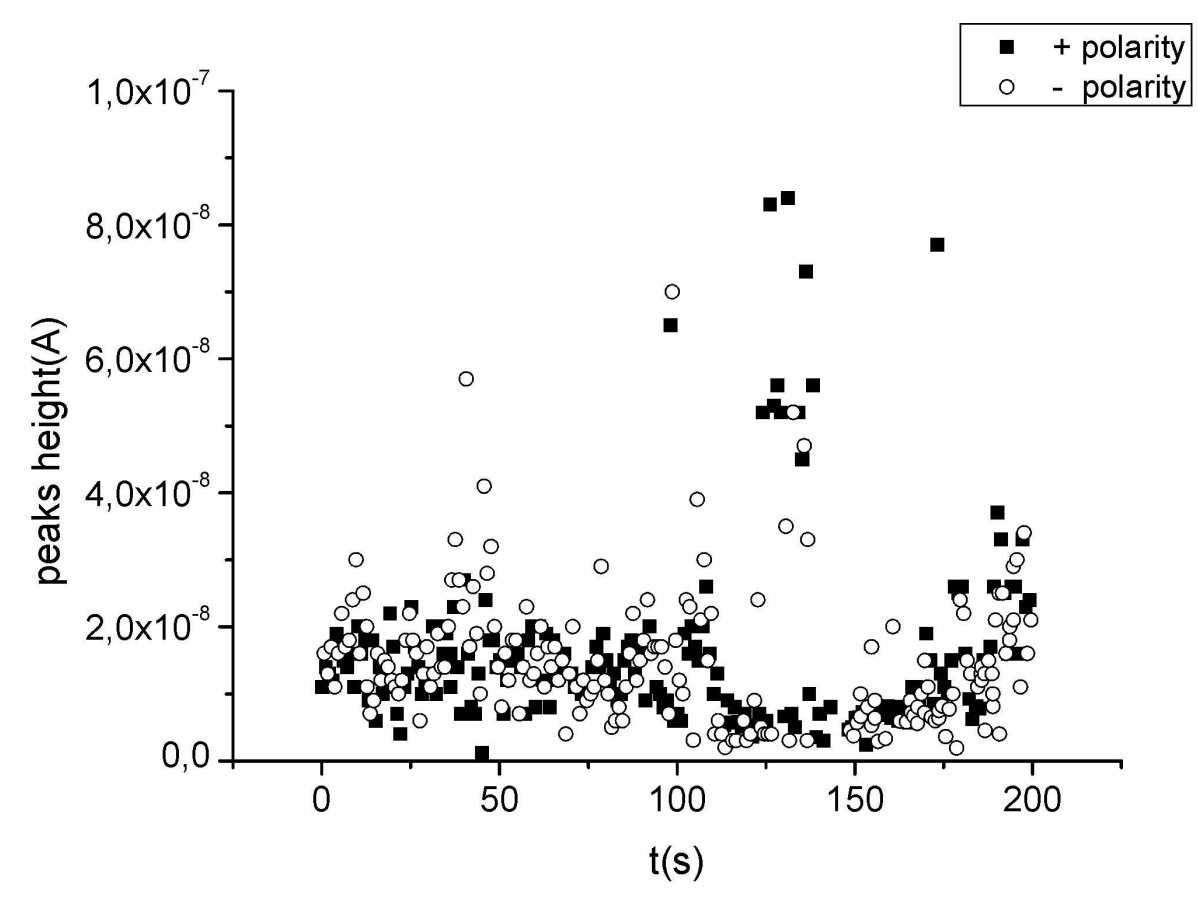

\section{FIGURE 4}

fig 4

$113 \times 96 \mathrm{~mm}(500 \times 500$ DPI $)$ 


1
2
3
4
5
6
7
8
9
10
11
12
13
14
15
16
17
18
19
20
21
22
23
24
25
26
27
28
29
30
31
32
33
34
35
36
37
38
39
40
41
42
43
44
45
46
47
48
49
50
51
52
53
54
55
56
50
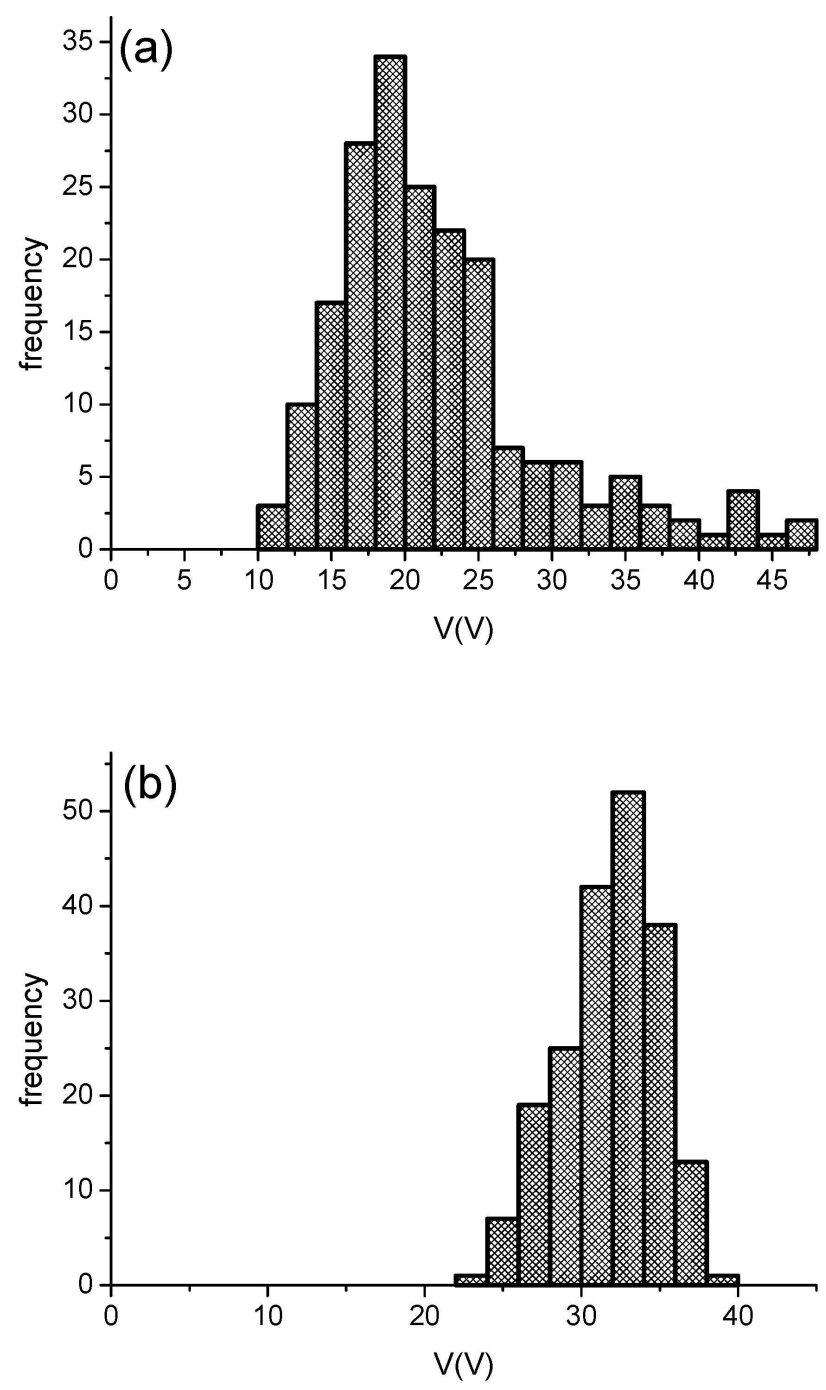

\section{FIGURES 5}

fig 5 $99 \times 171 \mathrm{~mm}(500 \times 500 \mathrm{DPI})$ 


1
2
3
4
5
6
7
8
9
10
11
12
13
14
15
16
17
18
19
20
21
22
23
24
25
26
27
28
29
30
31
32
33
34
35
36
37
38
39
40
41
42
43
44
45
46
47
48
49
50
51
52
53
54
55
56
57
59
60
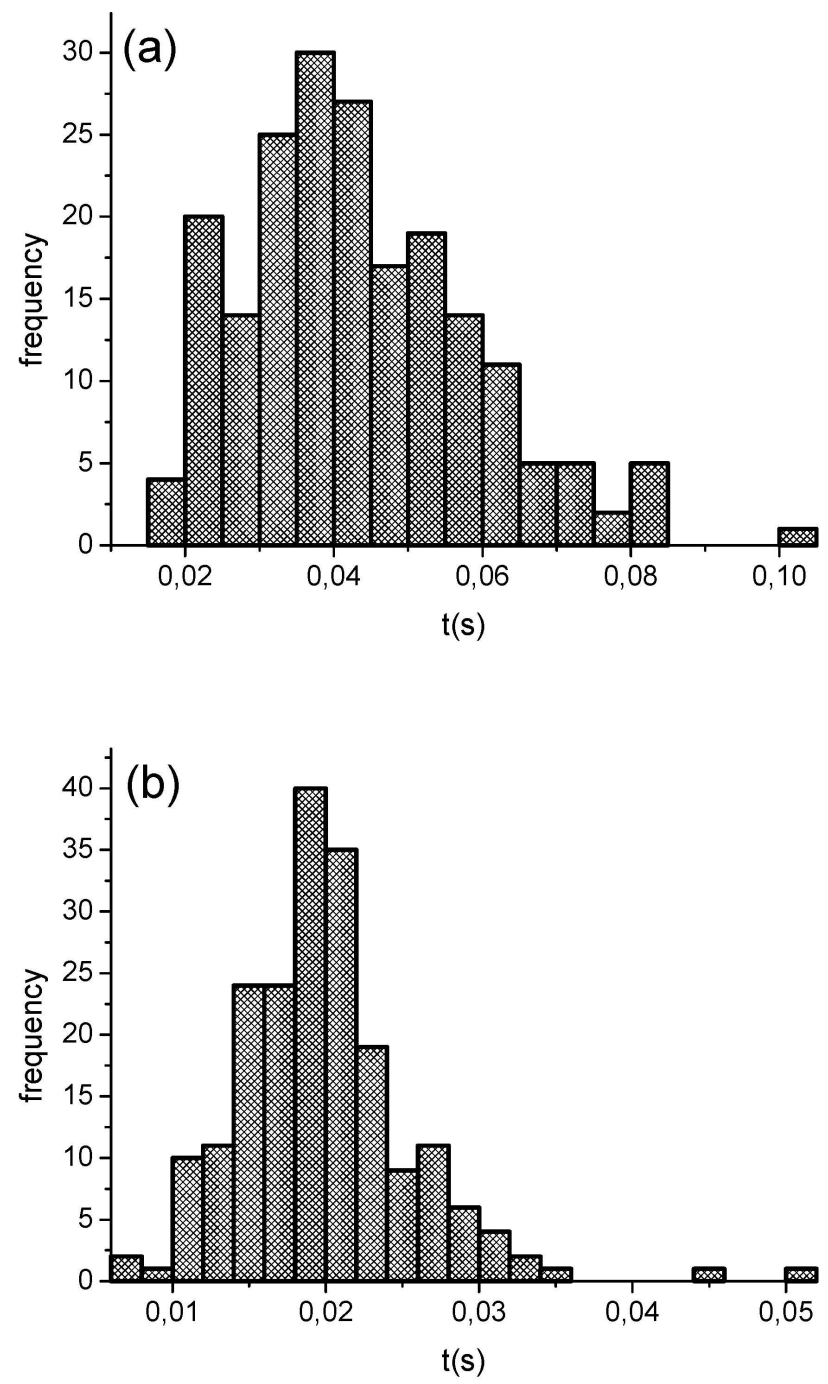

\section{FIGURES 6}

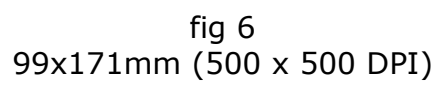

http://mc.manuscriptcentral.com/pm-pml 


1
2
3
4
5
6
7
8
9
10
11
12
13
14
15
16
17
18
19
20
21
22
23
24
25
26
27
28
29
30
31
32
33
34
35
36
37
38
39
40
41
42
43
44
45
46
47
48
49
50
51
52
53
54
55
56
50
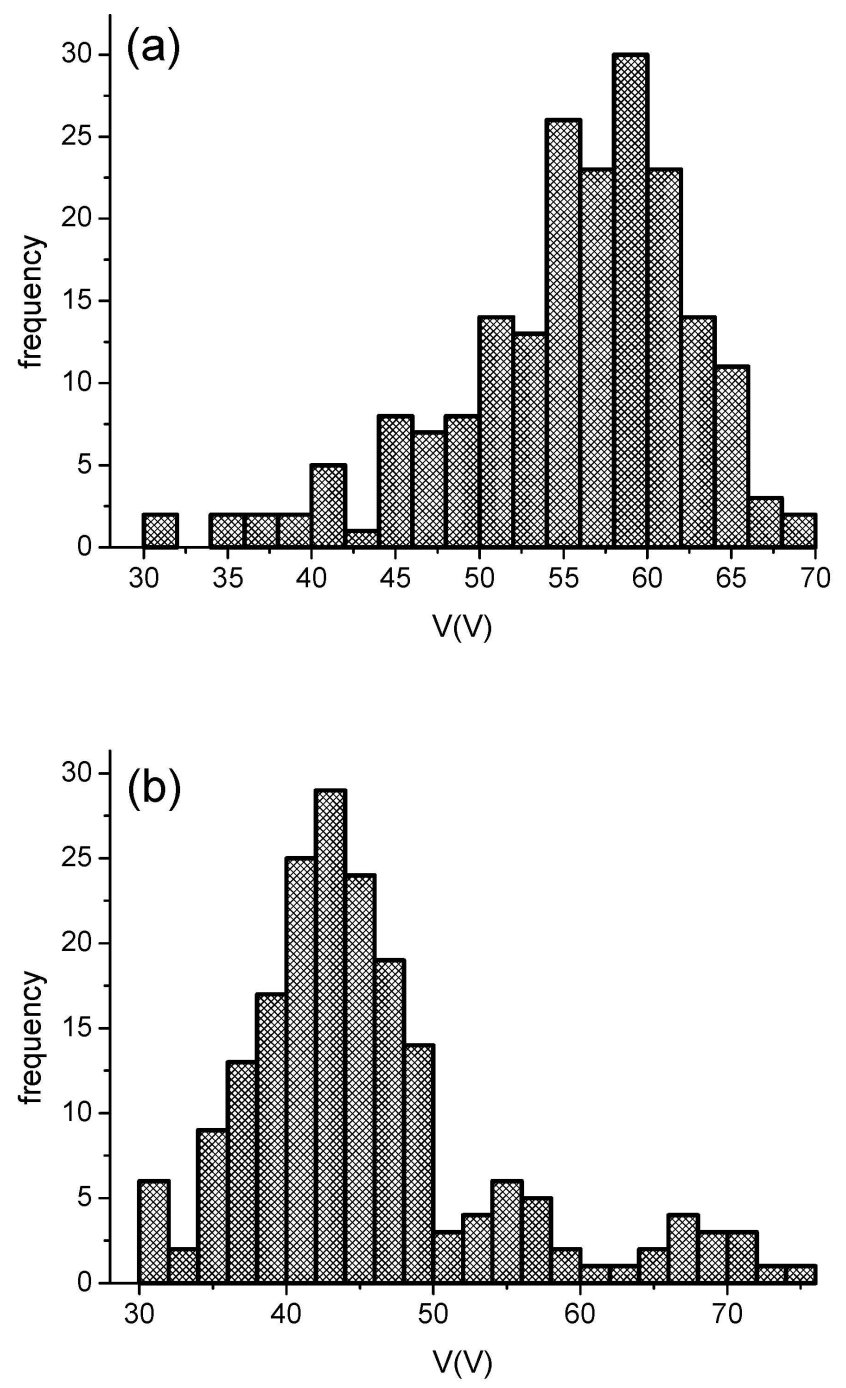

\section{FIGURES 7}

fig 7 $99 \times 171 \mathrm{~mm}(500 \times 500 \mathrm{DPI})$ 

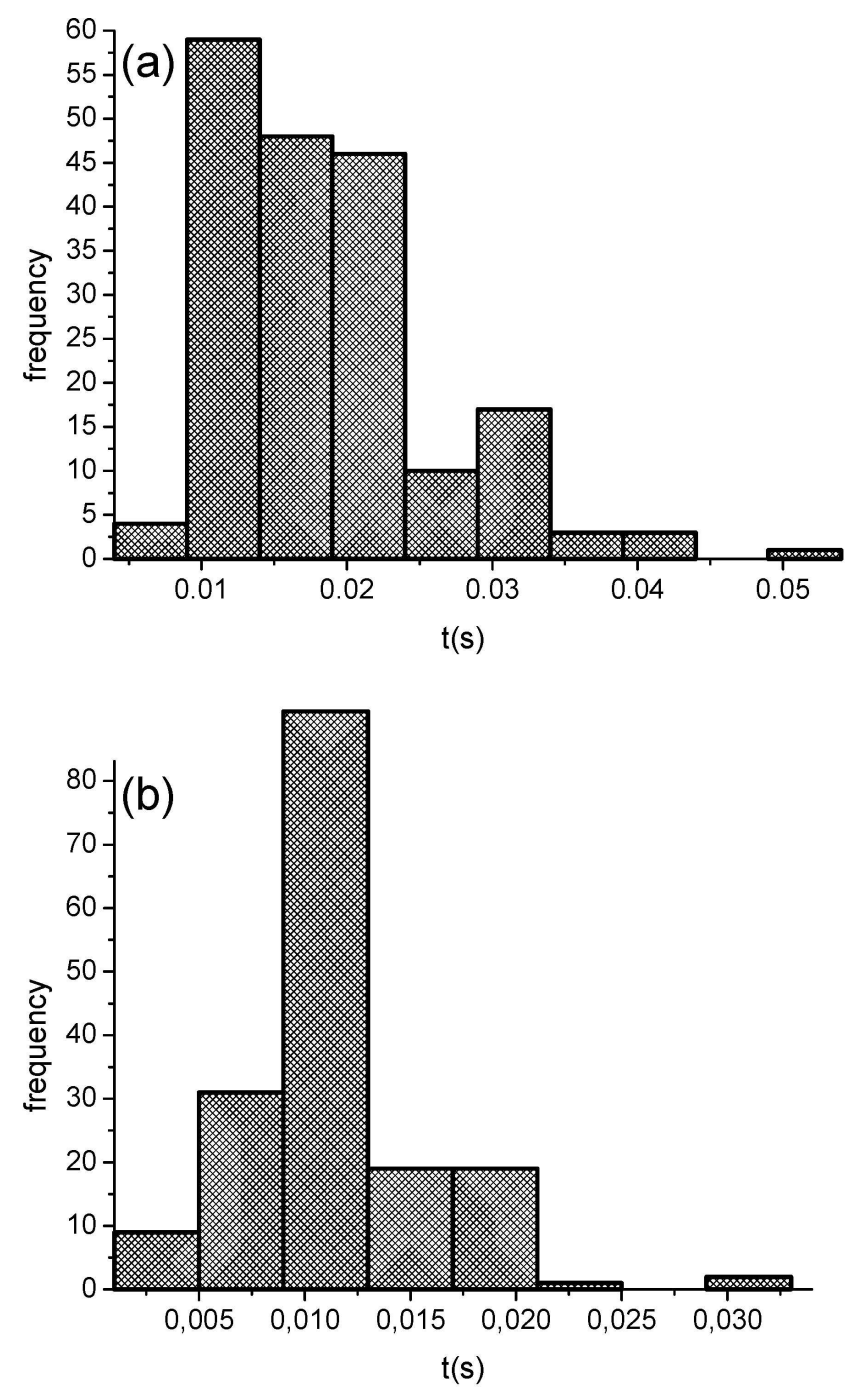

\section{FIGURES 8}

fig 8 $99 \times 172 \mathrm{~mm}(500 \times 500 \mathrm{DPI})$ 
a) Without electron contribution
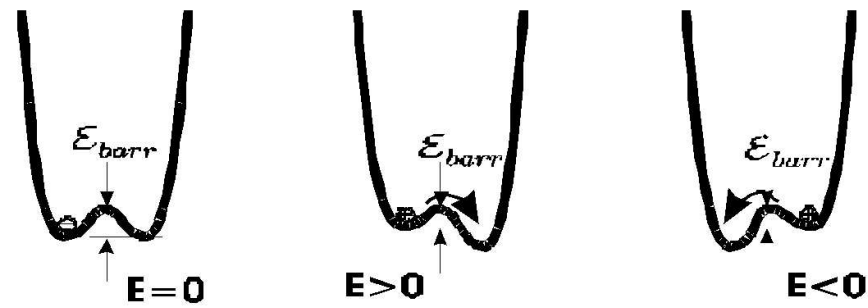

b) With electron contribution
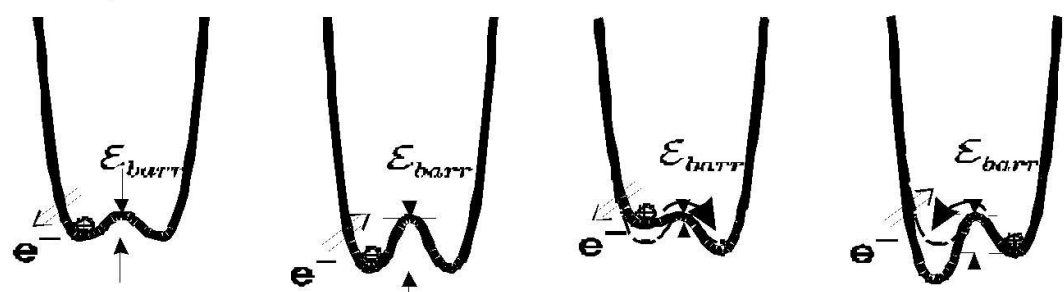

$$
E=0
$$$$
E=0
$$

$\mathbf{E}>\mathbf{0}$

$E<0$

\section{FIGURE 9}

fig 9

$161 \times 134 \mathrm{~mm}(500 \times 500 \mathrm{DPI})$ 